\title{
The role of different sliding resistances in limit analysis of hemispherical masonry domes
}

\author{
E. Mousavian, C. Casapulla \\ University of Napoli Federico II, Department of Structures for Engineering and Architecture, Italy \\ elham.mousavian@unina.it,casacla@unina.it
}

\begin{abstract}
A limit analysis method for masonry domes composed of interlocking blocks with non-isotropic sliding resistance is under development. This paper reports the first two steps of that work. It first introduces a revision to an existing limit analysis approach using the membrane theory with finite hoop stresses to find the minimum thickness of a hemispherical dome under its own weight and composed of conventional blocks with finite isotropic friction. The coordinates of an initial axisymmetric membrane surface are the optimization variables. During the optimization, the membrane satisfies the equilibrium conditions and meets the sliding constraints where intersects the block interfaces. The results of the revised procedure are compared to those obtained by other approaches finding the thinnest dome. A heuristic method using convex contact model is then introduced to find the sliding resistance of corrugated interlocking interfaces. Sliding of such interfaces is constrained by the Coulomb's friction law and by the shear resistance of the locks keeping the blocks together along two orthogonal directions. The role of these two different sliding resistances is discussed and the heuristic method is applied to the revised limit analysis method.
\end{abstract}

KEYwORDS. Computer aided conceptual design; Structurally informed design; Limit analysis; Interlocking blocks; Non-isotropic sliding resistances; Network of forces.

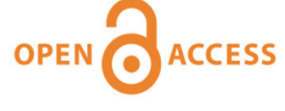

Citation: Mousavian, E., Casapulla, C., The role of different sliding resistances in limit analysis of hemispherical masonry domes, Frattura ed Integrità Strutturale, 51 (2020) 336-355.

Received: 19.06 .2019

Accepted: 19.11.2019

Published: 01.01.2020

Copyright: (C) 2019 This is an open access article under the terms of the CC-BY 4.0, which permits unrestricted use, distribution, and reproduction in any medium, provided the original author and source are credited.

\section{INTRODUCTION}

his paper reports a part of an ongoing research on the development of limit analysis for hemispherical domes composed of interlocking blocks. The paper covers two main issues. It first introduces a revision of the limit analysis framework proposed by D'Ayala and Casapulla [1] using the membrane theory for the hemispherical dome under its own weight. Then, the heuristic formulations previously proposed for $2 \mathrm{D}$ semicircular masonry arches with interlocking blocks [2] are extended to 3D interlocking interfaces within the hemispherical domes, by using a convex contact model [3]. 
In the literature, 2D thrust-line, membrane, and 3D thrust-network [4, 5], along with convex and concave contact models $[3,6,7]$, have been developed within the limit analysis framework to find the ultimate load factor (or the minimum thickness) for the feasible models of masonry structures. Referring to basic geometries, 2D thrust-line and membrane were applied to find the limit equilibrium of semi-circular arches [8-16], hemispherical domes [17-20] and vaults of given geometries including skew arches, and pavilion, cross and groin vaults [21-26]. Finding the ultimate load factor, together with the stress state and failure mechanisms for models with basic geometries, is a classical problem also solved through other structural analysis methods such as Finite Element (FE) analysis, including detailed and simplified finite element micro models [27-29], and Discrete Element (DE) analysis [30-32]. On the other hand, further approaches have been proposed to simplify the static and dynamic analysis of masonry structures assumed as assemblages of rigid blocks, such as equivalent macro-elements constituted by a set of trusses to describe masonry vaults [33] and one-sided motion of rocking rigid blocks $[34,35]$. However, limit analysis approach is less computationally expensive still highly accurate, compared to other computational methods.

According to the limit analysis approach applied to assemblages of rigid blocks, the stability of a block masonry structure is obtained when the internal forces distributed at block interfaces satisfy two physical constraints: the forces normal to the interfaces should be in compression and the forces tangential to the interfaces must be less than the interface sliding resistance, including associative [3, 6] or non-associative [36, 37] isotropic frictional resistance.

D'Ayala and Casapulla [1] developed a limit analysis procedure to find the minimum thickness required for a hemispherical masonry dome composed of rigid blocks with finite isotropic friction, to withstand a weight-like load distribution. That work first proved that due to the symmetry of geometry and loading, this configuration belongs to a special class of non-associative friction problems for which unique solutions within standard limit analysis can be found. This solution is the optimized axisymmetric membrane surface that everywhere lies within the thickness of the dome and satisfies equilibrium and frictional constraints. The resistant surface is characterised by meridional and hoop stresses, and it was observed that its profile might not coincide with the mid hemispherical surface for small frictional resistances. This means that the curvature of its generating meridian is not known a-priori and is generally not constant. So, in the cited paper, a meridional thrust-line per unit length of parallels (circle of latitude) was constructed by connecting a set of control points on the blocks, assumed as the optimization variables. The objective function of the optimization was to determine the coordinates of these control points for the unique membrane surface placed in the thinnest structure, satisfying the equilibrium condition and sliding constraints. To develop the sliding constraint, the stress state at the points where interfaces intersect the mentioned thrust-line was calculated.

In the first part of this paper, the equilibrium formulations and the sliding constraints presented in the mentioned work [1] are to some extent revisited, since in that work the sliding constraint in the parallel direction was not very accurate. Furthermore, the revised method can present the stress states at block interfaces through the construction of the membrane or discrete network of forces for the lunes of the dome.

The second part of this paper addresses the extension of limit analysis to interlocking interfaces with non-isotropic sliding resistance. In the literature, the sliding behaviour of interlocking blocks with different geometries has been taken into the consideration very recently. For example, the in-plane and out-of-plane capacity of masonry walls with blocks having corrugated interfaces have lately been studied through experimental and numerical investigations [38-40]. Particularly interesting is the numerical simulation of brick infill walls with locks along vertical interfaces under out-of-plane loading, developed by means of an innovative discrete macro-modelling strategy [41]. Dyskin et al. [42] and Estrin et al. [43] carried out an experimental test to evaluate the out-of-plane behaviour of osteomorphic blocks, while the out-of-plane capacity of a wall with blocks having cross shaped locks, keeping the blocks together, was demonstrated in [44] through experimental investigations. Furthermore, different structural behaviours of three types of joinery connections with different geometric properties were addressed in [45], experimentally and numerically.

Herein, the convex contact model proposed in [2] for 2D interlocking interfaces is adopted and extended to perform the orthotropic sliding behaviour of 3D corrugated hoop interfaces with locks having rectangular cross section (Fig. 1). This behaviour is governed by the Coulomb's friction law in one direction and by the shear resistance of the locks in the orthogonal direction. A heuristic method using this contact model is then introduced to find the sliding resistance of such interlocking blocks. The geometry of their interfaces is idealized and a relation between the geometric parameters of the locks, i.e. $g \times b \times b$ (width $\times$ length $\mathrm{x}$ height), including their orientation and number and the sliding resistance of the interfaces, is defined (Fig. 1).

In the following sections, the revisited limit analysis and optimization of the hemispherical dome proposed in the cited work [1] is first presented. The results obtained by this revisited procedure are compared with the previous ones and the extension of this analysis to hemispherical domes composed of interlocking blocks is discussed, in terms of a construction 
of a discrete network of forces. Then, the proposed convex contact model and the heuristic method to find the sliding resistance of the assumed interlocking blocks are developed and the conclusions of the work are finally provided.

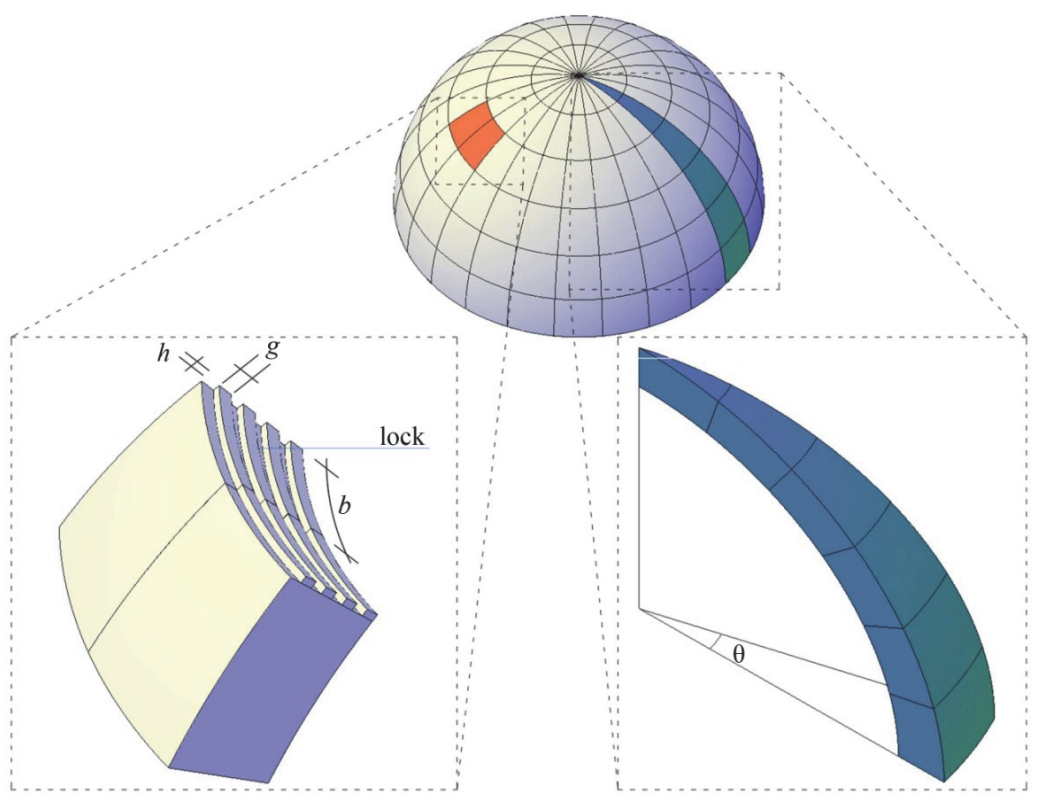

Figure 1: A hemispherical dome, a lune depicted in blue and two interlocking blocks presented in red. An interlocking block has several locks on its hoop face whose geometric properties including width $g$, height $b$ and length $b$ affect the sliding resistance of the block.

\section{LIMIT ANALYSIS OF HEMISPHERICAL DOMES COMPOSED OF CONVENTIONAL RIGID BLOCKS}

$\mathrm{T}$ he objective of the optimization is to find the minimum constant thickness of a stable hemispherical dome under its own weight, with assigned radius. To develop the optimization method, first a number of control points representing the blocks are defined and the axisymmetric membrane surface is constructed.

Applying the discrete approach of O'Dwyer [5] within the limit analysis framework, a network of forces can represent the structural model of the dome. A discretized dome includes a set of similar lunes (Fig. 1), each of them spanning horizontal angle $\theta=2 \pi / n l$, where $n l$ is the number of lunes (Fig. 1). Each lune also includes a set of similar rigid blocks stacked over each other.

The network of forces is constructed using a set of control points located on the blocks. A set of horizontal parallel polygons and a set of similar meridional thrust-lines pass through these control points. Decreasing the horizontal angle $\theta$, and therefore the length of the lune support, the centroids of the blocks move horizontally and radially towards the midsurface of the dome, while the parallel polygons tend to become circular. For unit length of parallels (of the hemisphere), the network of forces becomes very close to a membrane surface for the hemispherical dome [1] and the generating meridional trust-line can be called base thrust-line.

Given the symmetry of the problem, only half of the dome is considered in the proposed procedure. The generic trustlines with the coordinates of two subsequent control points for a lune with horizontal angle $\theta=\pi$ (i.e. for half dome), with $\theta<\pi$, and the base thrust-line are represented in Fig. 2 by a broken line, a dashed line, a dash-dotted line, respectively. The half dome is modelled by assuming that its mass is distributed along its mid hemispherical surface of radius $\mathrm{R}$ (its projection on the plane $\mathrm{XZ}$ is represented by the central-arc $\mathrm{C}$ in Fig. 3). To determine the coordinates of the control points of the base thrust-line, first the central-arc C (and the unknown thickness as well) is divided into the desired number of blocks $r$. Considering the mid-points of all the blocks (empty red circles in Fig. 3a), their $x$ coordinates coincide with the $x$ coordinates of the control points (filled red circles in Fig. 3b). Two different thrust-lines for the lunes with horizontal angle $\theta=\pi$ and $\theta<\pi$ are also constructed through interpolation of the points (depicted by orange and yellow dots in Fig. $2 \mathrm{a}$ and b, respectively) whose $x$ coordinates are different from the control points on the base thrust-line. Therefore, a different superscript of $x$ is used for the different lengths of the considered lunes. On the other hand, the $z$ coordinates of the control points of the base thrust-line are the same as those of the thrust-lines of lunes $\theta$ and $\pi$, and no 
superscript is used for them. It is worth noting that, in the following, indices $i$ and $j$ are respectively used to enumerate blocks and interfaces between the blocks from the apex (point A) to the support (point B), i.e. interface $j$ is the lower interface of block $i$.

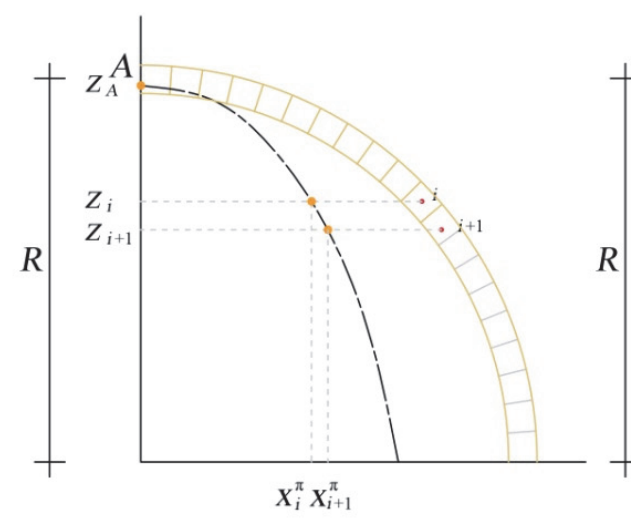

—_- Thrust-line for Lune $\pi$

(a)
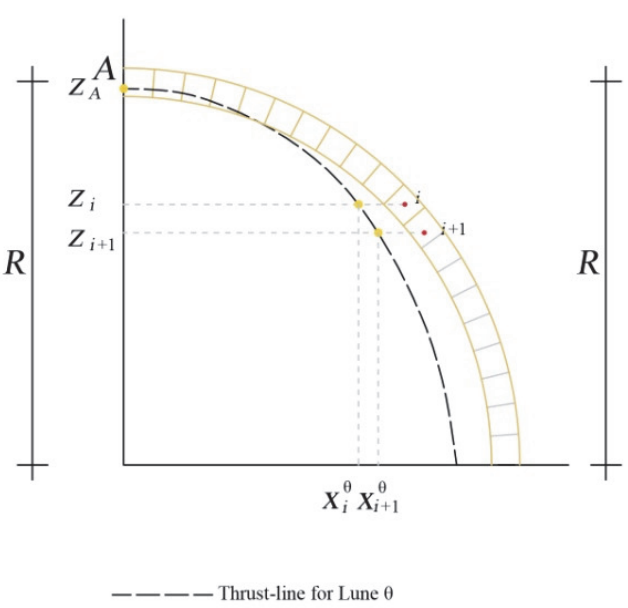

(b)

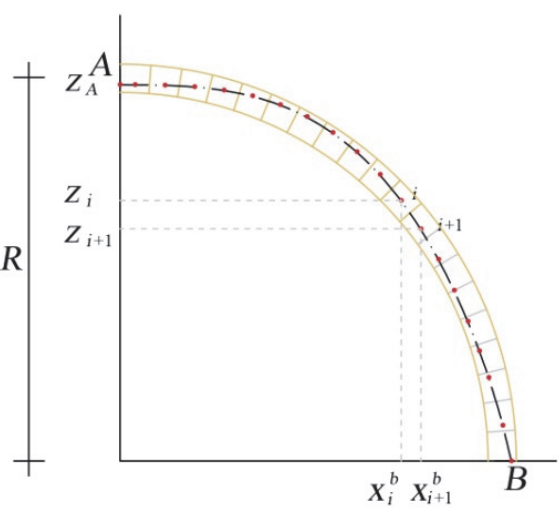

$-\cdot-$ base thrust-line

(c)

Figure 2. Thrust-lines for the a) half dome, b) lune with $\theta<\pi$, and c) base thrust-line.

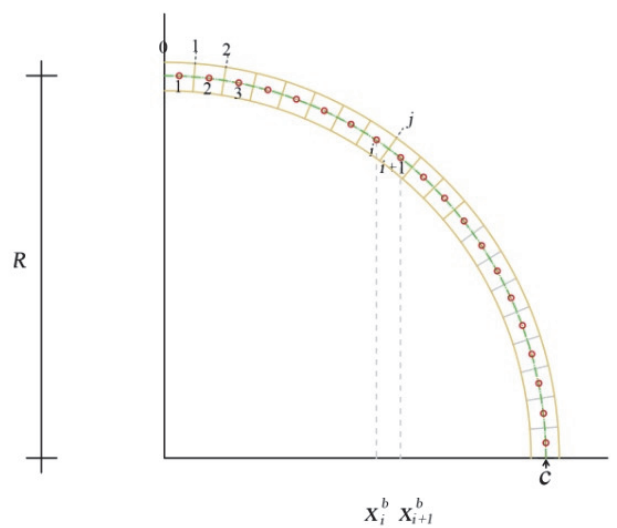

(a)

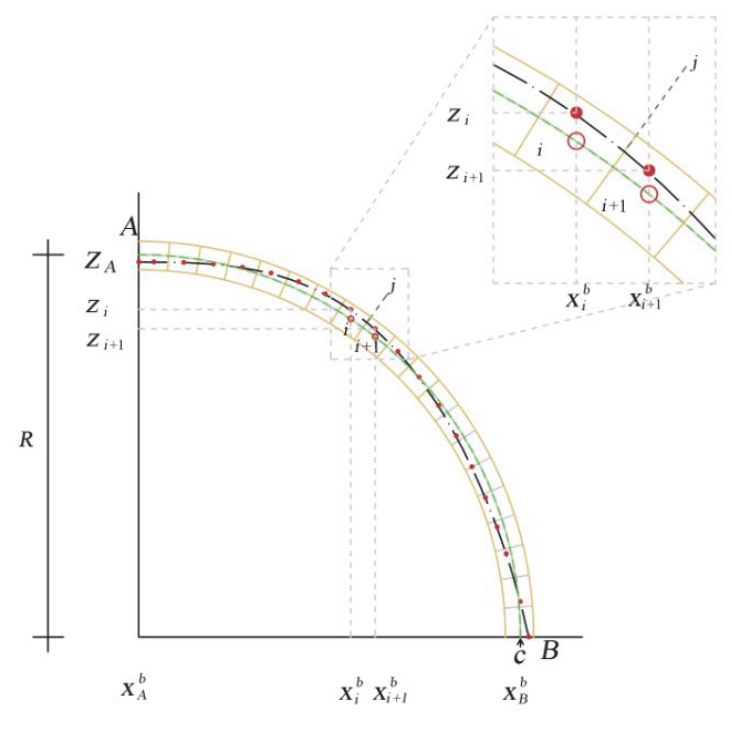

(b)

Figure 3: Coordinates of the centroids of blocks on the a) central-arc $\mathrm{C}$ and of the control points on the b) base thrust-line, with the enumeration of blocks and their interfaces.

The $z$ coordinates of the control points constructing the base thrust-line are the variables of the optimization objective function $f\left(z_{i}\right)$. For a set of control points with coordinates $x_{i}^{b}$ and $z_{i}$ modelling a base thrust-line, half of the thickness for the dome is obtained as $\max \left[\sqrt{\left(x_{i}^{b}\right)^{2}+\left(z_{i}\right)^{2}}-R\right]$. As a result, the objective function of the optimization is:

$$
f\left(z_{i}\right): t / 2=\operatorname{Min} \max \left[\sqrt{\left(x_{i}^{b}\right)^{2}+\left(z_{i}\right)^{2}}-R\right]
$$

where $t$ is the minimum thickness of the masonry dome. 
Given the isostatic nature of the problem, for any given set of descending zis the state of stress is completely defined by simple equilibrium equations, so allowing the construction of any corresponding axisymmetric membrane surface. In other words, the value of zis are only bounded by the sliding constraint. Finding the state of stress of the equilibrated model, this constraint is determined, as described in the following

First consider the section with an angle of embrace $\alpha_{j}$ of half dome divided into a number of rows equal to the number of blocks along the meridional length. Being $\omega$ the weight for unit surface, the total weight of this section is:

$$
W_{j}^{\pi}=\omega \pi R^{2}\left(1-\cos \alpha_{j}\right)
$$

passing through the centre of mass of the half dome section (Fig. 4a). The $x$ coordinate of this centre is:

$$
x_{m j}^{\pi}=\frac{\sum_{i=1}^{j}\left(W_{i}^{\pi} x_{i}^{\pi}\right)}{W_{j}^{\pi}}
$$

where $W_{i}^{\pi}$ is the weight of the corresponding row on the half dome and $x_{i}^{\pi}$ is the $x$ coordinate of block $i$ on the thrust-line for $\theta=\pi$ (Figs. 4b). The z coordinates of this point and control point $i$ on the base thrust-line are identical.

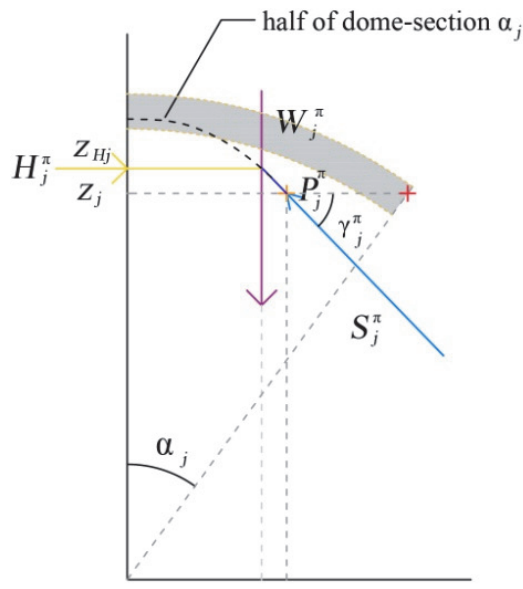

$\boldsymbol{X}_{\mathrm{w} j}^{\pi} \quad \boldsymbol{X}_{j}^{\pi}$

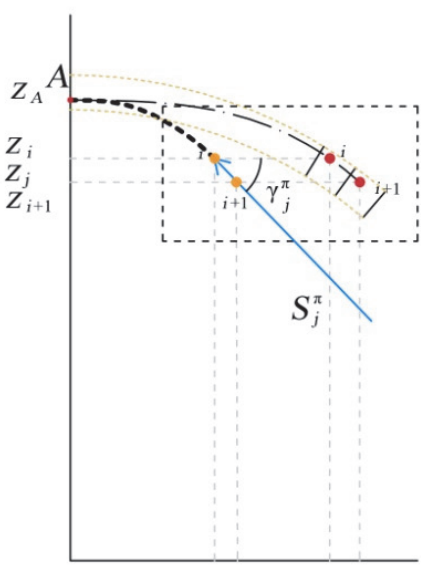

$\begin{array}{llll}X_{i}^{\pi} & X_{i+1}^{\pi} & X_{i}^{b} & X_{i+1}^{b}\end{array}$

(b)

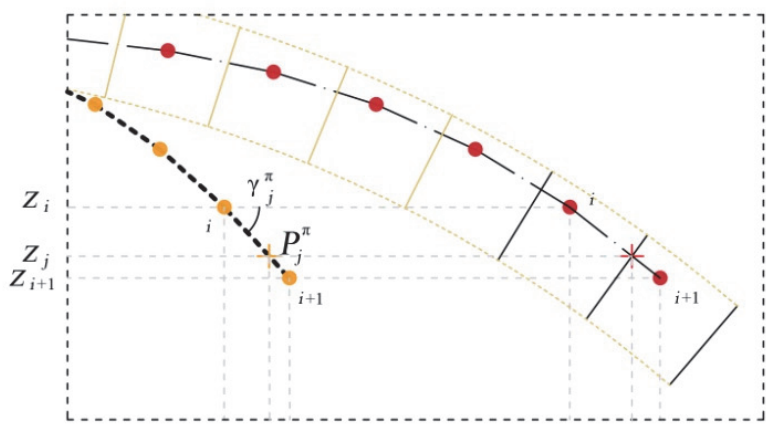

$X_{i}^{\pi} X_{j}^{\pi} X_{i+1}^{\pi}$

$\boldsymbol{X}_{i}^{b} \quad \boldsymbol{X}_{j}^{b} \boldsymbol{X}_{i+1}^{b}$

(c)

(a)

Figure 4: Thrust-lines and details for the half dome with an angle of embrace $\alpha_{j}$.

The angle $\gamma_{j}^{\pi}$ between the meridional force resultant on interface $j\left(S_{j}^{\pi}\right)$ of the half dome and the horizontal line at point $\mathrm{P}_{j}^{\pi}\left(\chi_{j}^{\pi}, z_{i}\right)$, shown in Fig. $4 \mathrm{a}$, can be defined both from the global equilibrium of the section and from the construction of the corresponding thrust-line.

In fact, the rotational equilibrium of the section $\alpha_{j}$ of half dome about point $\mathrm{P}_{j}^{\pi}$ requires the horizontal hoop force resultant $H_{j}^{\pi}$ to be applied to a point with $\gtrless_{H j}$ coordinate, so that:

$$
H_{j}^{\pi}=W_{j}^{\pi} \frac{x_{j}^{\pi}-x_{m j}^{\pi}}{z_{H j}-z_{j}}=\frac{W_{j}^{\pi}}{\tan \gamma_{j}^{\pi}}
$$

from which the angle $\gamma_{j}^{\pi}$ can be derived. On the other hand, $\gamma_{j}^{\pi}$ also corresponds to the inclination of the thrust-line between the control points of block $i$ and $i+1$ when $\theta=\pi$ (Fig. 4c), i.e.:

$$
\tan \gamma_{j}^{\pi}=\frac{z_{i}-z_{i+1}}{x_{i+1}^{\pi}-x_{i}^{\pi}}
$$


Using Eqns. (4) and (5) the following expression can be obtained:

$$
\tan \gamma_{j}^{\pi}=\frac{z_{H j}-z_{j}}{x_{j}^{\pi}-x_{m j}^{\pi}}=\frac{z_{i}-z_{i+1}}{x_{i+1}^{\pi}-x_{i}^{\pi}}
$$

from which a value of $z_{H j}$ can also be derived for each $\alpha_{j}$. Moreover, considering that $x_{i}^{\pi}=\left(2 / \pi x_{i}^{b}\right)$, the following relation between the angle $\gamma_{j}^{\pi}$ and the corresponding one $\gamma_{j}^{b}$ on the base thrust line (representing the inclination of the meridional force resultant $S_{j}^{b}$ on interface $j$ ) is:

$$
\tan \gamma_{j}^{\pi}=\frac{\pi}{2} \frac{z_{i}-z_{i+1}}{x_{i+1}^{b}-x_{i}^{b}}=\frac{\pi}{2} \tan \gamma_{j}^{b}
$$

as represented in Figs. $5 \mathrm{a}$ to $5 \mathrm{c}$ which refer to the same dome section but per unit length of parallels. It is worth noting that $z_{H j}$ is the same for both representations of the dome section.

Similarly, it can be demonstrated that:

$$
H_{j}^{\pi}=2 x_{j}^{b} H_{j}^{b}
$$

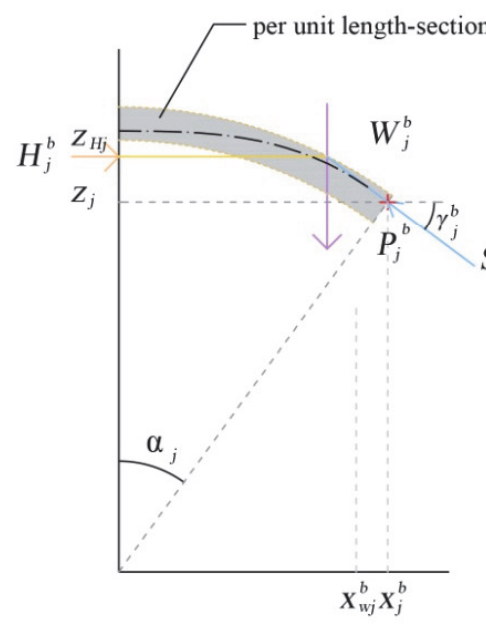

(a)

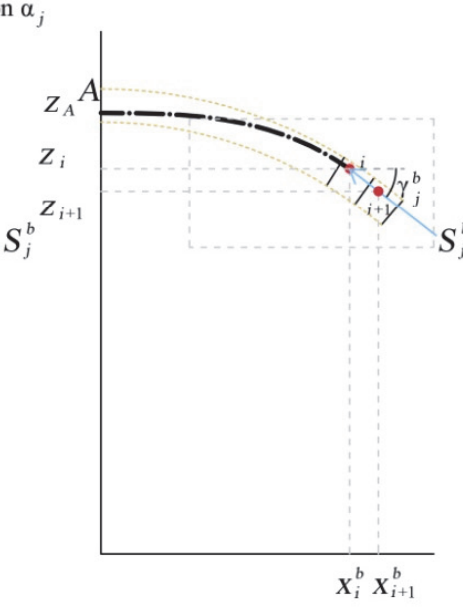

(b)

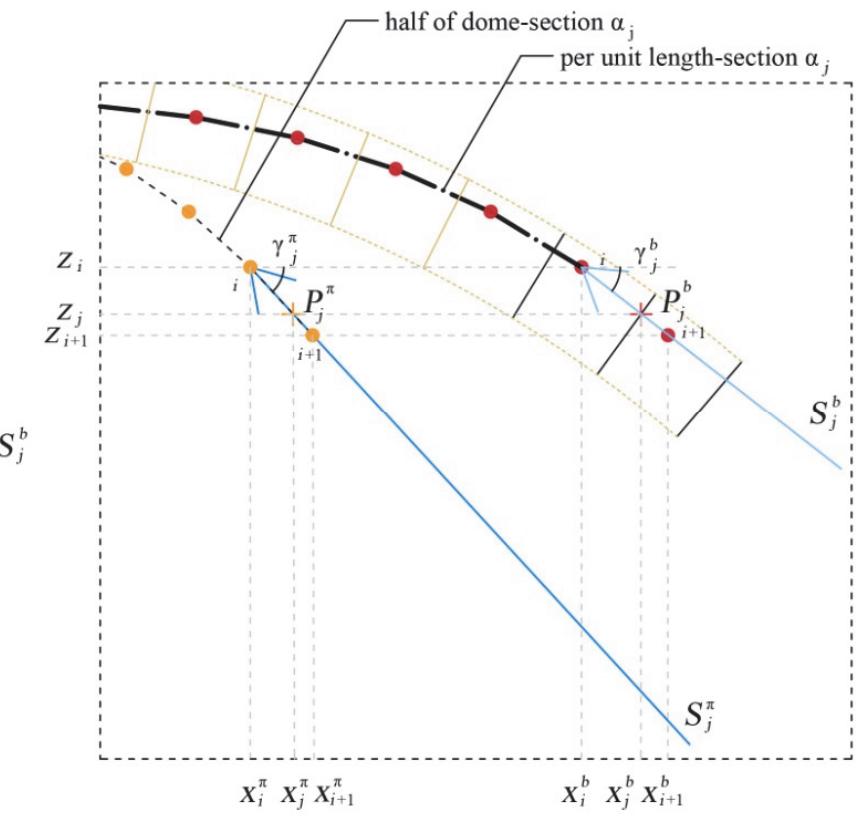

(c)

Figure 5: Thrust-lines and details for the lune per unit length of parallels (base thrust-line).

In sum, taking into account Eqns. (6) and (7), the equilibrium of the dome section with angle of embrace $\alpha_{j}$ simply requires that:

$$
z_{H j}=z_{j}+\left(x_{j}^{b}-x_{m j}^{b}\right) \tan \gamma_{j}^{b}
$$

where:

$$
\tan \gamma_{j}^{b}=\frac{z_{i}-z_{i+1}}{x_{i+1}^{b}-x_{i}^{b}} \quad \quad z_{j}=\frac{z_{i}+x_{i}^{b} \tan \gamma_{j}^{b}}{1+\tan \alpha_{j} \tan \gamma_{j}^{b}} \quad \text { and } x_{j}^{b}=z_{j} \tan \alpha_{j}
$$


Eqns. (9) and (10) easily allow the calculation of the meridional and hoop forces of the constructed membrane surface.

Finding the stress state through the equilibrium equations, the sliding constraint is defined by limiting the maximum values of the internal shear force to be not greater than the frictional resistance at each block interface. This limitation can be imposed independently on the two contributions obtained by the meridional and hoop force resultants so that two states of presence and absence of hoop forces can be analysed.

With reference to the meridional sliding constraint (in the absence of hoop forces), it is observed that the internal force $S_{j}^{b}$ at interface $j$ per unit length of parallels is distributed uniformly on the intersected circular arc. According to the Coulomb's friction law, the sliding constraint can be written as (Fig. 6):

$$
\left|T_{j}^{b}\right| \leq \mu N_{j}^{b}
$$

where $\mu$ is the friction coefficient and $T_{j}^{b}$ and $N_{j}^{b}$ are the components of $S_{j}^{b}$ tangential and normal to interface $j$, respectively, expressed by the formulations:

$$
\begin{aligned}
& T_{j}^{b}=S_{j}^{b} \sin \left(\alpha_{j}-\gamma_{j}^{b}\right) \\
& N_{j}^{b}=S_{j}^{b} \cos \left(\alpha_{j}-\gamma_{j}^{b}\right)
\end{aligned}
$$

As a result, in Eqn. (11) can be rewritten as:

$$
\left|\tan \left(\alpha_{j}-\gamma_{j}^{b}\right)\right| \leq \mu
$$

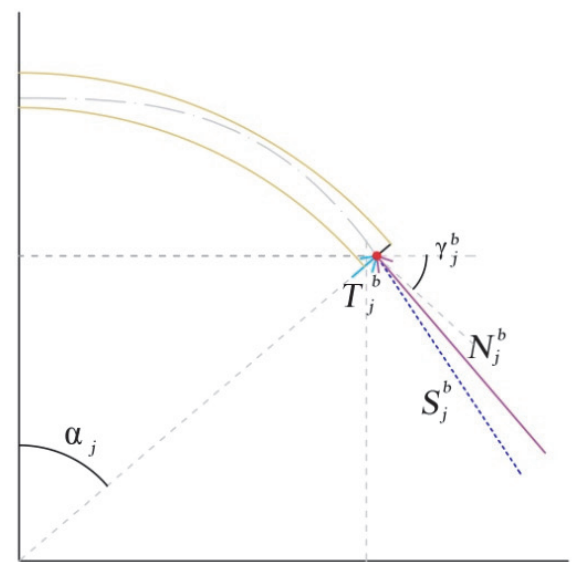

Figure 6: Meridional sliding constraint at interface $j$ governed by tangential and normal components of $S_{j}^{b}$.

With reference to the parallel sliding constraint, first the horizontal resultant of the hoop stresses per unit length of parallels $H_{i}^{b}$ for each block $i$ can be found by taking into account Eqns. (4) and (8), i.e. (Figs. 7a and 7b):

$$
H_{i}^{b}=H_{j}^{b}-H_{j-1}^{b}
$$

which is applied at the control point at level zi. This force is applied horizontally outwards when positive (showing compressive hoop forces) and inwards when negative (presenting tensile hoop forces).

Then, due to the geometry of the hemispherical dome and its composing blocks, inward movement of the upper portion of the dome over the lower one at interface $j$ is not possible. This means that only limiting hoop force $H^{b}{ }_{j}$, im against outward movements must be considered as frictional resistance at this interface and that, including the contribution of the meridional force, the normal and tangential components of the resultant at interface $j$ can be respectively written as: 


$$
\begin{aligned}
& N_{j, \lim }^{b}=S_{j}^{b} \cos \left(\alpha_{j}-\gamma_{j}^{b}\right)+H_{j, \lim }^{b} \cos \alpha_{j} \\
& T_{j, \lim }^{b}=S_{j}^{b} \sin \left(\alpha_{j}-\gamma_{j}^{b}\right)+H_{j, \lim }^{b} \sin \alpha_{j}
\end{aligned}
$$

Taking into account that $T_{j}^{b}$, lim $=\mu N_{j}^{b}$,lim, the limiting hoop force resultant $H_{j, \text { lim }}^{b}$ is:

$$
H_{j, \lim }^{b}=\frac{S_{j}^{b}\left[\mu \cos \left(\alpha_{j}-\gamma_{j}^{b}\right)-\sin \left(\alpha_{j}-\gamma_{j}^{b}\right)\right]}{\sin \alpha_{j}-\mu \cos \alpha_{j}}
$$

So, the parallel sliding constraint can be formulated as:

$$
\left|H_{i}^{b}\right| \leq\left|H_{j, \lim }^{b}-H_{j-1, \lim }^{b}\right|
$$

It should be observed that this constraint is more accurate than that proposed in the previous work [1] and therefore different results can be expected.
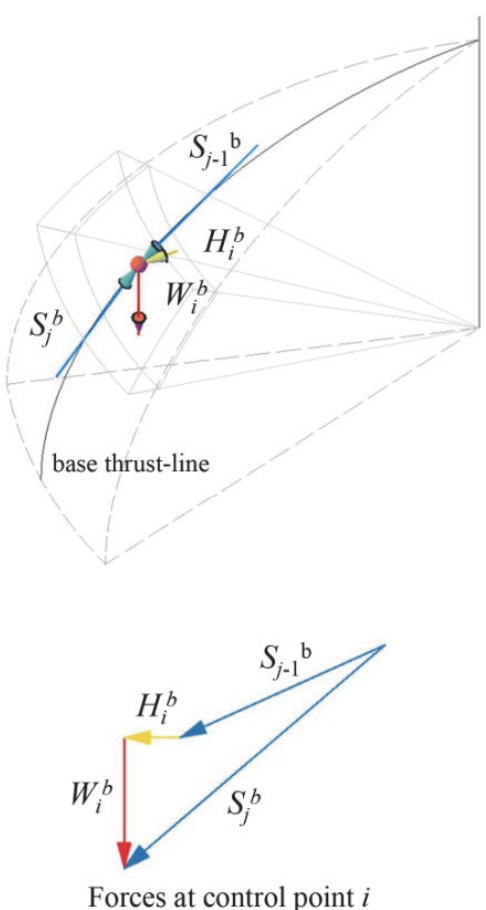

(a)
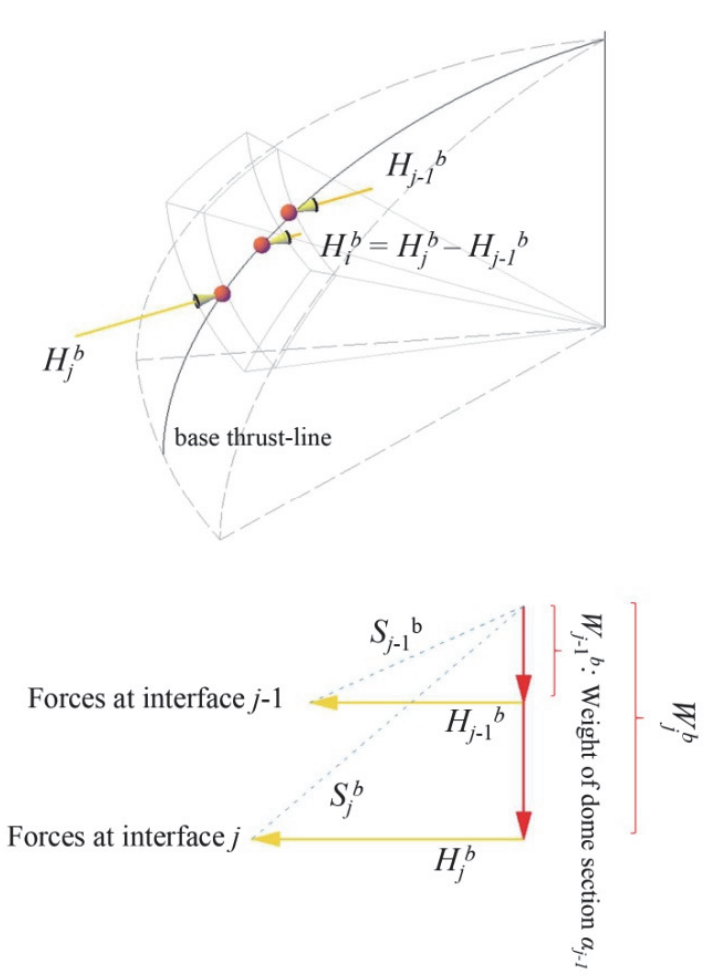

(b)

Figure 7: a) Resultant of the hoop stresses $H_{i}^{b}$ per unit length of parallels passing through the corresponding control point at level $q_{i}$ and equilibrium diagram for forces per unit length of parallels; b) meridional forces at the two interfaces $\left(S_{j-1}{ }^{b}\right.$ and $\left.S_{j}^{b}\right)$ whose horizontal components are $H_{j-1}{ }^{b}$ and $H_{j}^{b}$, respectively.

Lastly, the optimization problem can be stated as follows:

$$
t / 2=\operatorname{Min} \max \left[\sqrt{\left(x_{i}^{b}\right)^{2}+\left(z_{i}\right)^{2}}-R\right]
$$




$$
\begin{aligned}
& \text { S.T. } \\
& \left|\tan \left(\alpha_{j}-\gamma_{j}^{b}\right)\right| \leq \mu \quad \text { meridional sliding constraint } \\
& \left|H_{i}^{b}\right| \leq\left|H_{j, \lim }^{b}-H_{j-1, \lim }^{b}\right| \text { parallel sliding constraint }
\end{aligned}
$$

It is worth highlighting that the parallel sliding constraint is particularly suitable to the stability of a dome composed of an assemblage of blocks with running bond pattern, while it does not work in presence of stacked bond pattern, where zero hoop forces must be considered. In this case, in fact, the problem reduces to the one of an arch of increasing width from the crown to the spring, obtained by cracks along the meridional interfaces between adjacent lunes, and the value of minimum thickness to span ratio as a safe solution was first provided by Heyman[17] under the assumptions of infinite compressive strength and friction resistance and zero tensile strength. The corresponding minimum thickness represents an upper bound of the real solution. On the other hand, the classical membrane theory with unlimited hoop forces provides zero thickness of the hemispherical dome, representing the lower bound solution. The solution provided by the approach herein proposed is a membrane surface with limited hoop forces and the minimum thickness required is expected to be in the range of the lower and upper bounds.

\title{
RESULTS
}

case study of a hemispherical dome with $10 \mathrm{~m}$ centreline radius, containing 20 rows and 20 lunes under its own weight was optimized. The obtained results were then compared to the results obtained by other existing methods.
\end{abstract}

To model the dome, construct the membrane and implement part of the structural analysis, C\# component of Grasshopper was applied. The outputs of the optimization including the final model were obtained through the Grasshopper environment as well. Grasshopper is a visual programming language which runs within Rhinoceros 3D. The core of structural analysis and optimization was done by MATLAB used as backend. To solve the minimax problem (19), the MATLAB's fminimax method was implemented [46].

Fig. 8 graphically shows the relationship between the normalised minimum thickness of a structurally feasible dome and the coefficient of friction at block interfaces obtained by the proposed approach and by other existing methods introduced by $[1,17,31]$. The curve "Heyman's cracked model" [17] represents the classical solution of a dome already cracked along the meridians (zero hoop forces) but satisfying the meridional sliding constraint according to Eqn. (14). In fact, this model yields a constant value of the $t / R$ ratio of 0.0425 if the friction coefficient $\mu$ is greater than 0.25 . For $\mu<0.25$, the resultant of meridional stresses reaches a limit value on some block interface (according to Eqn. (4)) and the minimum thickness increases sharply. As expected, this upper bound solution is not very far from the proposed curve "Revised membrane with zero hoop forces", which is based on the same assumptions. Instead, the curves "Membrane with limited hoop forces" obtained by D'ayala and Casapulla [1] and "Revised membrane with limited hoop forces" herein proposed represent the solutions obtained by a similar optimization procedure but with a slightly different sliding constraint on the hoop forces, as described above. In particular, the approach herein proposed provides more conservative results with respect to the previous one, still included in the described range of solutions, whose lower bound is represented by the horizontal curve "Classical membrane with unlimited hoop forces". Lastly, the "Discrete element approach" [31] still considering hoop resistances at interfaces (unlike the Heyman's cracked approach), provides results closer to the Heyman's model than to the models with limited hoop forces, even if for $\mu>0.23$ the curve decreases similarly.

On the other hand, the results of all approaches present the same pattern, characterized by three domains of the friction coefficient. First, no equilibrium is possible when $\mu$ is so small $\left(\mu<\mu_{1}\right)$, where $\mu_{1}$ is the minimum value. For larger values of $\mu$ so that $\mu_{1}<\mu<\mu_{2}$ (where $\mu_{2}$ is the value marking a clear change in the curve inclination), the ratio of minimum thickness to radius $t / R$ decreases (linearly or non-linearly) and the dome behaves as a cracked dome with mixed sliding and rocking mechanisms governed by the meridional sliding constraint (three hinges at the extrados and intrados of each lune are formed and the sliding mechanism occurs at the lowest interface of the lune). Instead, when $\mu$ is large enough $\left(\mu>\mu_{2}\right)$, sliding along the lower parallels can occur for the models considering the presence of limited hoop forces or, in case of zero hoop forces, pure rocking mechanism can be observed on the optimal result so that four hinges are formed at the intrados and extrados of each cracked lune. 
Using different approaches, different $\mu_{1}$ and $\mu_{2}$ were calculated. The results in terms of both values of $\mu$ and the corresponding $t / R$ are reported in Tab. 1, starting from the proposed approach. It is first interesting to observe that while the thickness of dome for any $\mu$ between $\mu_{1}$ and $\mu_{2}$ given by Heyman's method is larger than the corresponding result obtained by the proposed approach for the dome with stacked bond pattern (zero hoop forces), the minimum thicknesses for $\mu>\mu_{2}$ are almost similar using the two approaches. Moreover, using discrete element analysis of Simon and Bagi [31], the results for $\mu_{1}<\mu<\mu_{2}$ are closer to the proposed approach than to the Heyman's method, while those for $\mu>\mu_{2}$ are similar to the decreasing curves for limited hoop forces.

The last remark is that the results obtained by the proposed method for domes with running bond pattern (limited hoop forces) are slightly different from those given by the membrane approach [1], herein revised. The reason is to be found in the different parallel sliding constraint that governs this part of the curve, as described above. Instead for $\mu>\mu_{2}$ these are in good agreement and both shows that for values of $\mu \geq 0.7$ the minimum thickness required by that formulation is infinitely small as the membrane surface tends to coincide with the mean hemispherical surface of the dome, which is considered the lower bound of possible solutions.

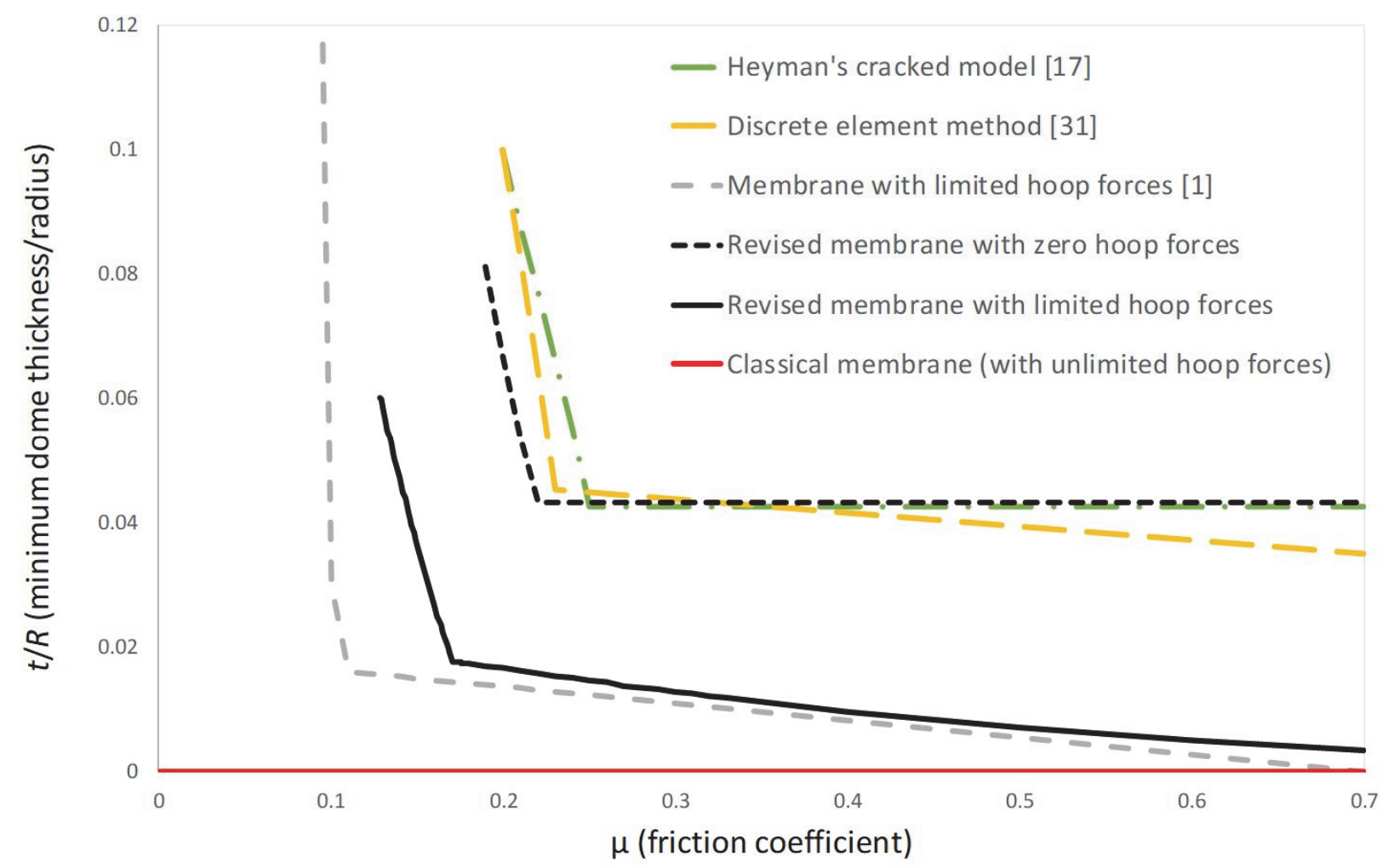

Figure 8: Relationship between the minimum thickness of a dome composed of conventional blocks and the coefficient of friction.

\begin{tabular}{ccccc}
\hline Approaches & $\mu_{1}$ & $\mu_{2}$ & $t / R\left(\mu=\mu_{1}\right)$ & $t / R\left(\mu=\mu_{2}\right)$ \\
$\begin{array}{c}\text { Revised membrane (zero } \\
\text { hoop forces) }\end{array}$ & 0.19 & 0.22 & 0.08 & 0.043 \\
$\begin{array}{c}\text { Revised membrane } \\
\text { (limited hoop forces) }\end{array}$ & 0.13 & 0.17 & 0.06 & 0.018 \\
$\begin{array}{c}\text { Membrane (limited hoop } \\
\text { forces) [1] }\end{array}$ & 0.09 & 0.11 & 0.20 & 0.016 \\
Heyman's model [17] & 0.20 & 0.25 & 0.10 & 0.043 \\
DEM approach [31] & 0.20 & 0.23 & 0.10 & 0.045 \\
\hline
\end{tabular}

Table 1: Compared results for the optimized hemispherical dome composed of conventional rigid blocks. 


\section{DISCRETE NETWORK OF FORCES FOR HEMISPHERICAL DOMES}

$\mathrm{A}$ s demonstrated above, the geometric properties of the interfaces between the blocks can be ignored in formulating the sliding constraint within the limit analysis framework. By contrast, using interlocking blocks, the geometric properties of the interfaces must be considered within the sliding constraints because the interface behaviour is not isotropic and the stress state at each interface must be found separately. To this aim, a discrete network of forces can be modelled with reference to meridional thrust-lines instead of base thrust-lines, while parallel polygons can still be assumed in compression or tension if the sliding resistances are met in different directions.

To construct the meridional thrust-line for the lune with horizontal angle $\theta$, first the relation between its meridional force $S_{j}^{\theta}$ and its corresponding force $S_{j}^{b}$ on the base thrust-line is determined. Given $W_{j}^{b}=\left[\omega \pi R^{2}\left(1-\cos \alpha_{j}\right)\right] /\left(\pi x_{j}^{b}\right)$ and $H_{j}^{b}$ as the two components of $S_{j}^{b}$ for the base thrust-line, the vertical and horizontal internal forces applied on interface $j$ of the lune with horizontal angle $\theta$ (as components of $S_{j}^{\theta}$ ) can respectively be found as (Fig. 9):

$$
\begin{aligned}
& W_{j}^{\theta}=W_{j}^{b} x_{j}^{b} \theta \\
& H_{j}^{\theta}=2 H_{j}^{b} x_{j}^{b} \sin \left(\frac{\theta}{2}\right)
\end{aligned}
$$

where $x_{j}^{b}$ is the $x$ coordinate of the point on interface $j$ at which forces are applied. Fig. 10 illustrates the relation between $H_{j}^{\theta}$ and $H_{j}^{b}$ (Eqn. (21)), graphically.
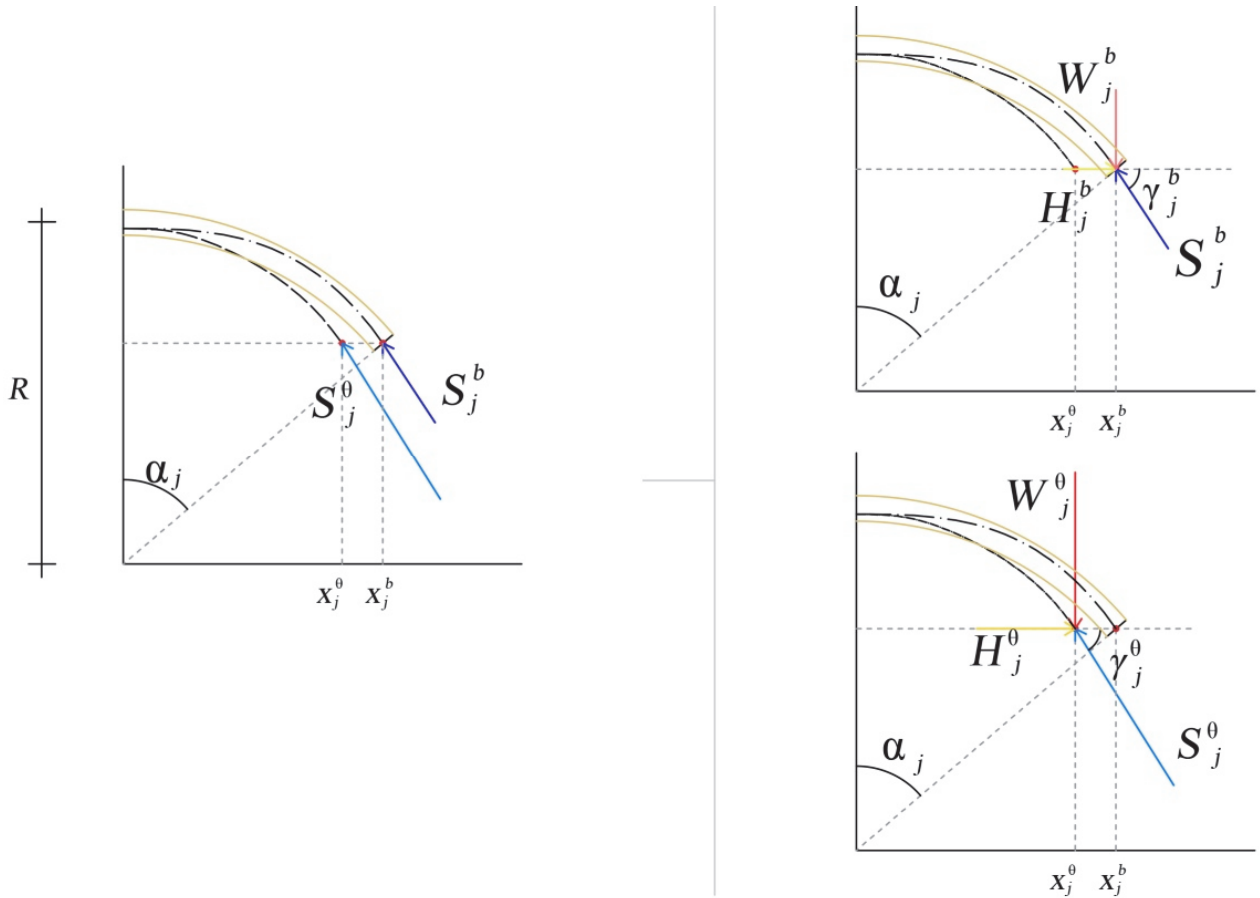

Figure 9: Relation between the meridional force $S_{j}^{\theta}$ for the lune with horizontal angle $\theta$ and the force $S_{j}^{b}$ for the base thrust-line.

Finding $W_{j}^{\theta}$ and $H_{j}^{\theta}$, the $x$ coordinate of centroid $i$, through which the thrust-line of the lune with horizontal angle $\theta$ passes $\left(x_{i}^{\theta}\right)$, can be computed through the following steps. Knowing the $x$ and $z$ coordinates of centroid $i$, the network of force can be constructed using these formulations:

$$
\frac{W_{j}^{\theta}}{H_{j}^{\theta}}=\frac{W_{j}^{b} x_{j}^{b} \theta}{2 H_{j}^{b} x_{j}^{b} \sin \left(\frac{\theta}{2}\right)} \Rightarrow \tan \gamma_{j}^{\theta}=\frac{\theta}{2 \sin \left(\frac{\theta}{2}\right)} \tan \gamma_{j}^{b}
$$


which can be rewritten as:

$$
\frac{z_{i}-z_{i+1}}{x_{i+1}^{\theta}-x_{i}^{\theta}}=\frac{\theta}{2 \sin \left(\frac{\theta}{2}\right)} \frac{z_{i}-z_{i+1}}{x_{i+1}^{b}-x_{i}^{b}} \Rightarrow \frac{x_{i+1}^{b}-x_{i}^{b}}{x_{i+1}^{\theta}-x_{i}^{\theta}}=\frac{\theta}{2 \sin \left(\frac{\theta}{2}\right)}
$$

Eqn. (23) for two control points $A$ and $\# 1$ is $\frac{x_{1}^{b}-x_{A}^{b}}{x_{1}^{\theta}-x_{A}^{\theta}}=\frac{x_{1}^{b}}{x_{1}^{\theta}}=\frac{\theta}{2 \sin \left(\frac{\theta}{2}\right)}$, since both $x_{\mathrm{A}}{ }^{\theta}$ and $x_{\mathrm{A}}^{b}$ are zero. Substituting $x_{1}^{b}$ with $[\theta /(2 \sin (\theta / 2))] x_{1}{ }^{\theta}$ in Eqn. (23) for control points 1 and 2 and then continuing it for every control points $i$ and $i+1$, the following equation is obtained:

$$
x_{i}^{b}=\frac{\theta}{2 \sin \left(\frac{\theta}{2}\right)} x_{i}^{\theta}
$$

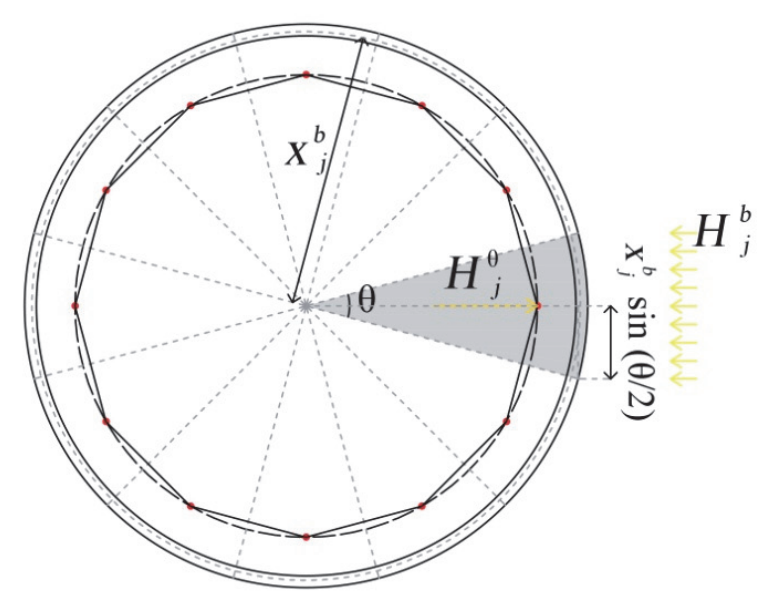

Figure 10: Graphic presentation of the relation between $H_{j}^{\theta}$ and $H_{j}^{b}$.

\section{CONVEX CONTACT MODEL FOR INTERLOCKING INTERFACES}

I $\mathrm{n}$ this section, an algorithm referred to a single interface with given orientation and number of locks is developed to demonstrate the sliding behaviour of the interlocking interfaces within a hemispherical dome. A numerical strategy is also proposed to idealize the stress state on this interface as a set of internal forces at one point on the interface, according to the convex contact formulation.

\section{Modelling of an interlocking interface in a hemispherical dome}

The hemispherical dome is composed of horizontal rows of blocks, which produce curved interfaces between blocks stacked over each other. The curved interface is a section of a cone, whose vertex is the hemisphere centre and whose base is a horizontal circle, as depicted in Fig. 11. If these interfaces, here called hoop interfaces, are designed to be interlocking, they can represent the curved surfaces where the locks are attached to the main bodies of the interlocked blocks. If the lock height is zero, each curved surface represents a row.

As a simple approximation, the hoop interface of each block is assumed to be flat and to be abstracted to a trapezoid shape, as depicted in Fig. 12a. Modelling an interface as a trapezoid enables us to develop numerical formulations to calculate the value of width $g$ and length $b$ of the locks affecting the sliding resistance (Fig. 12b). Finding the value of the geometric parameters through the numeric formulations reduces the computation time considerably. The formulas are presented later in this section.

Given the number $m$ and orientation $\varphi$ of locks, these can be modelled on a trapezoid face (Fig. 13), following the proposed steps: first, line $L$ is considered as the projection of the diameter $d$ or the longer base of the trapezoid $p$, 
depending on which projection is longer (Fig. 13b); then, line $L$ is divided to the given number of locks (Figs. 13c and 13d).
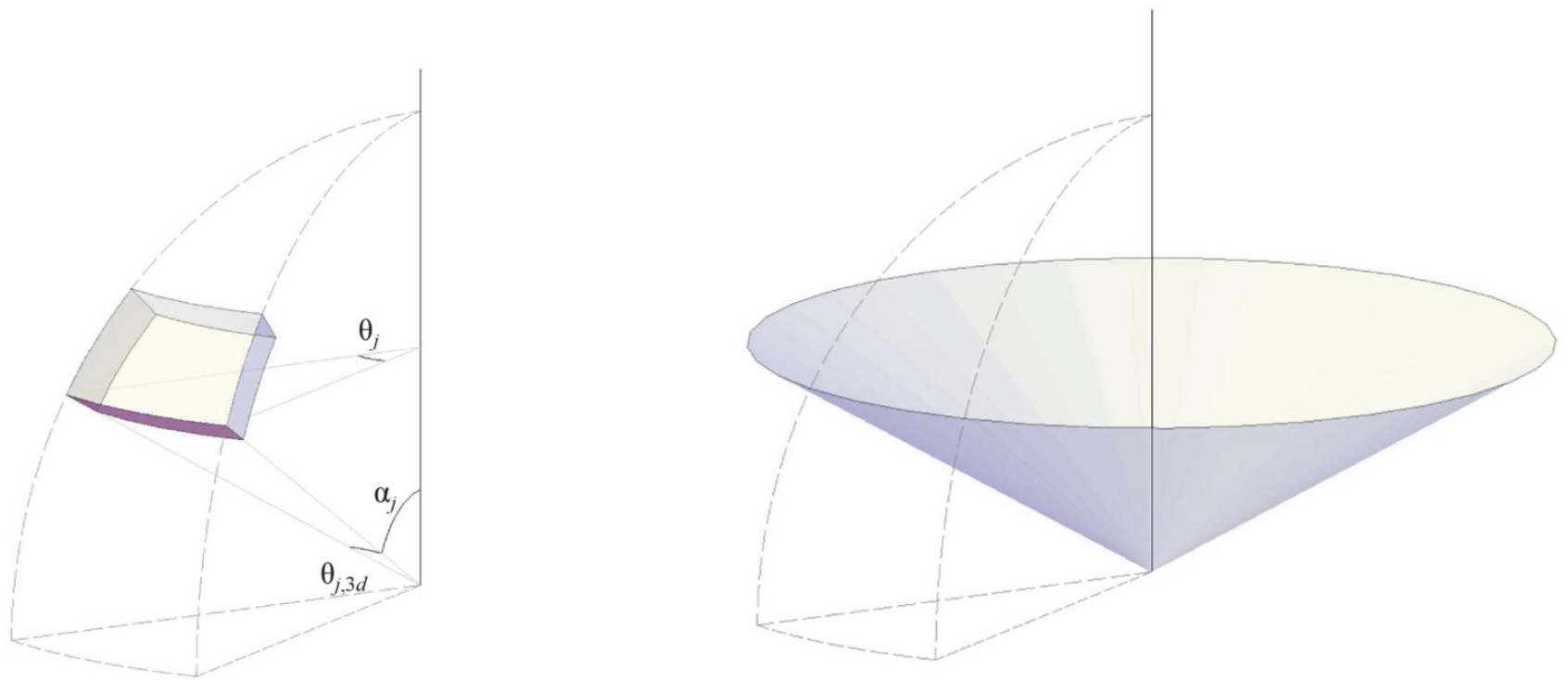

Figure 11: Curved interface $j$ within the hemispherical dome which is part of a cone.

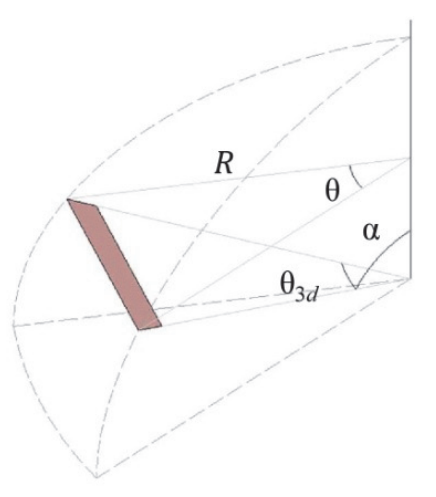

(a)
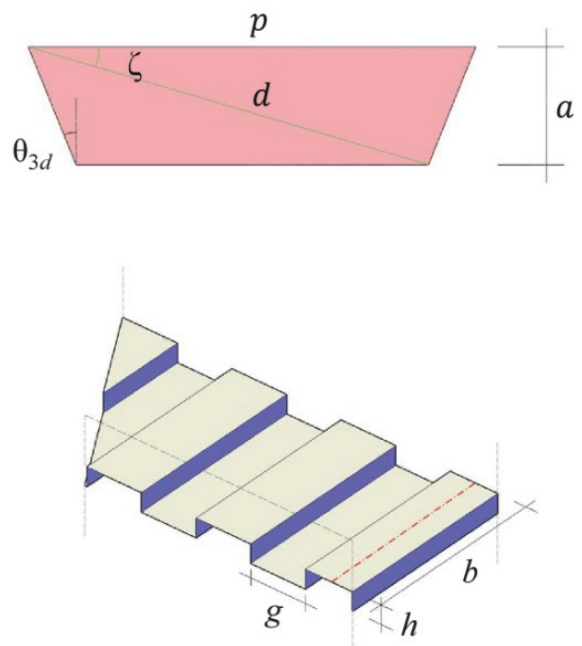

(b)

Figure 12: An abstracted interface for a block of the hemispherical dome and all the geometric properties involved in structural stability. The designer can adjust all these properties parametrically.

Knowing the length of $L$, the width of a lock $g$ equals $L / m$, where $m$ is the number of locks and $L$ is obtained as follows:

$$
L=\max (d|\cos (\zeta-\varphi)|, p \cos \varphi)
$$

where $d=a \sin \zeta ; p=\left(R+\frac{a}{2}\right) \theta_{3 d} ; \zeta=\arctan \frac{a}{p-a \tan \left(\frac{\theta_{3 d}}{2}\right)} ; \theta_{3 d}=2 \arctan \left(\tan \left(\frac{\theta}{2}\right) \sin \alpha\right)$. Parameters $a, \alpha, R$ and $\theta_{3 d}$ are depicted in Fig. 12. 

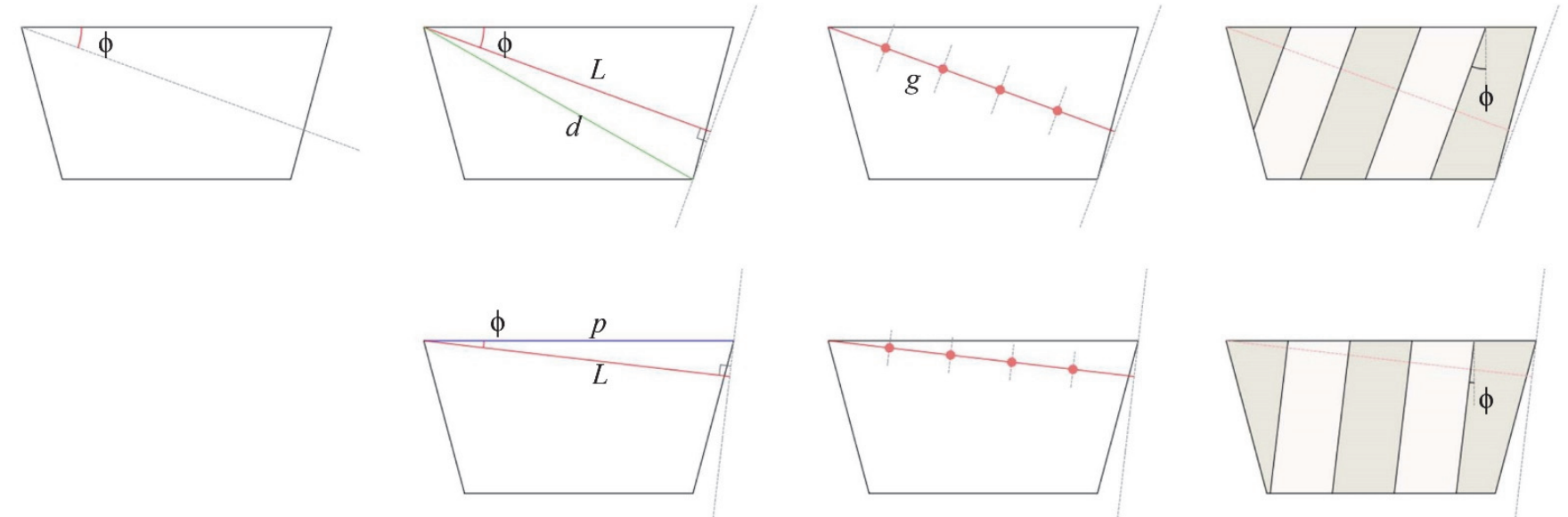

(b)

(c)

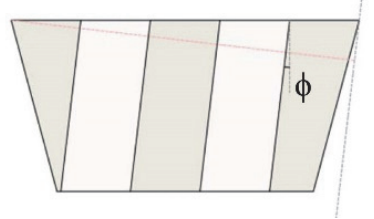

(a)

(d)

Figure 13: Modelling process to generate the interlocking interface, given the orientation and number of locks in four steps (a) to (d). There are two ways (two rows in the figure) for modelling an interlocking interface, depending on the length of the diameter $d$ and base of the trapezoid $p$.

In addition to $g$, the length of a lock centreline $b$ can also be formulated numerically. Depending on the location of a lock on an interface, three equations can determine this length. Fig. 14 shows three zones on a trapezoid, to which three corresponding intersection points of the lock centreline and $L$ (red point in Fig. 14) are associated, i.e.:

$$
\begin{aligned}
& L_{1}=\frac{a}{\cos \left(\frac{\theta_{3 d}}{2}\right) \cos \left(\frac{\theta_{3 d}}{2}+\varphi\right)} \\
& L_{2}=\min (d|\cos (\zeta-\varphi)|, p \cos \varphi)-L_{1} \\
& L_{3}=L-\left(L_{1}+L_{2}\right)
\end{aligned}
$$
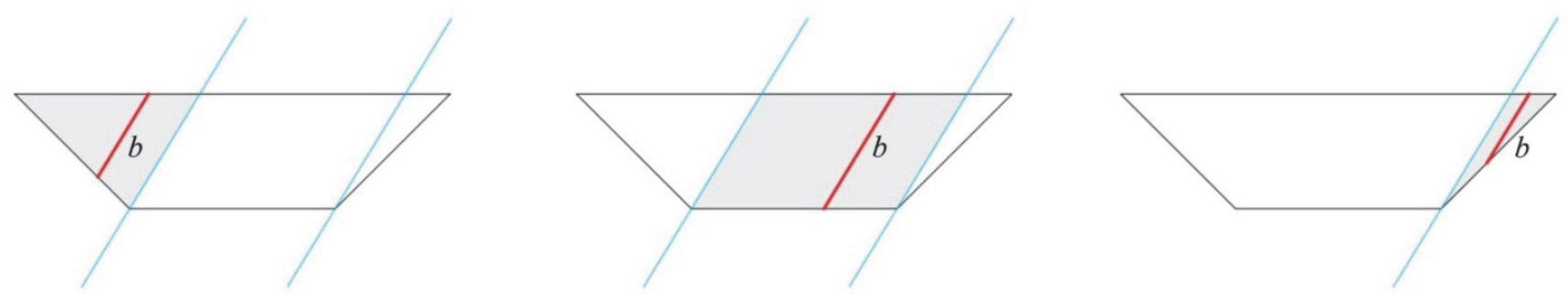

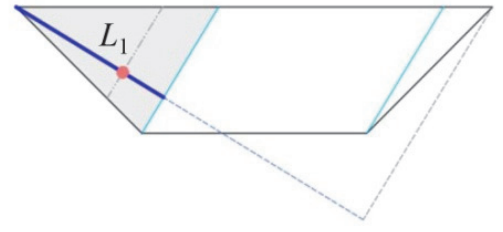

Zone 1

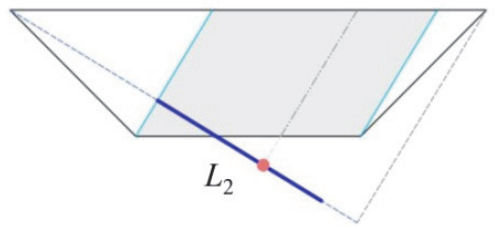

Zone 2

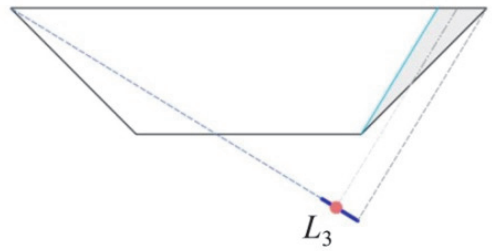

Zone 3

Figure 14: Three zones for calculation of the length of the lock $b$. 
Depending on if the intersection point locates on Zone 1, 2 or 3, the corresponding equations can be used to define the lock length $b$, respectively:

$$
\begin{aligned}
& b^{k}=\frac{g}{2} c_{k}\left[\tan \varphi+\cot \left(\frac{\theta_{3 d}}{2}+\varphi\right)\right] \\
& b^{k}=\frac{a}{\cos \varphi} \\
& b^{k}=\left\{\begin{array}{l}
\frac{\alpha}{\cos \varphi}-g\left[\left(m-\frac{c_{k}}{2}\right) \cot \left(\varphi-\frac{\theta_{3 d}}{2}\right)+\frac{c_{k}}{2} \tan \varphi\right],|d \cos (\zeta-\varphi)| \geq p \cos \varphi \wedge \zeta \geq \varphi \\
\cos \varphi \\
\left.-\left(m-\frac{c_{k}}{2}\right) \cot \left(\varphi-\frac{\theta_{3 d}}{2}\right)+\frac{c_{k}}{2} \tan \varphi\right],|d \cos (\zeta-\varphi)| \geq p \cos \varphi \wedge \zeta<\varphi \\
\left(m-\frac{c_{k}}{2}\right) g\left[\cot \left(\frac{\theta_{3 d}}{2}-\varphi\right)-\tan \varphi\right],|d \cos (\zeta-\varphi)| \leq p \cos \varphi
\end{array}\right.
\end{aligned}
$$

where coefficient $c_{k} \in\{1, \ldots, k+3(k-1), \ldots, 2 m-1\} ; k \in \mathbb{N}$.

\section{Sliding resistance of an interlocking interface in a bemispherical dome}

Fig. 15 presents a generic interlocking interface modelled as a set of failure strips where internal forces are distributed on. These planar strips include dry joints between two interlocking blocks (blue strips) and fracture planes at which the block can crack (red strips). Other kinds of fracture are avoided through considering the main body of the interlocking block rigid enough. A dry joint can be separated, rock, and slide along the locks, while a lock can be cracked at the fracture plane due to bending, shear, torsion or combinations of them.

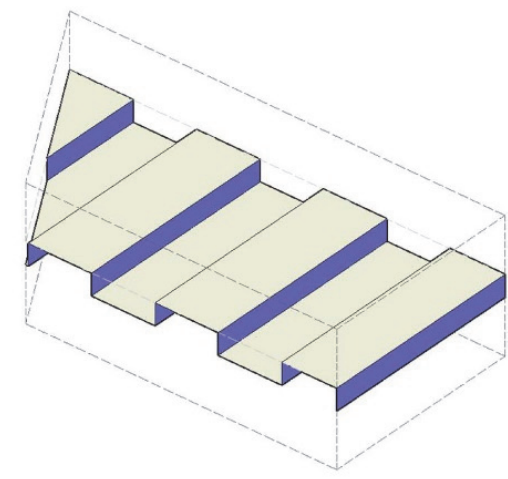

(a)

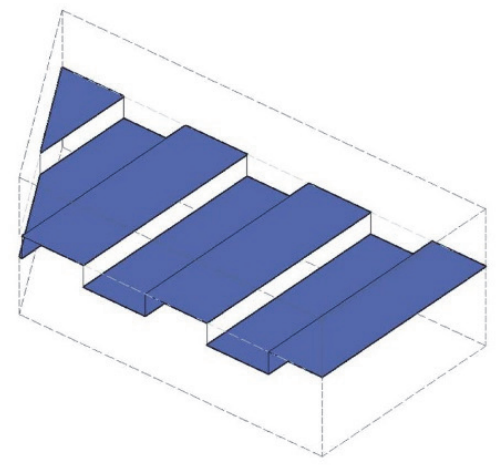

(b)

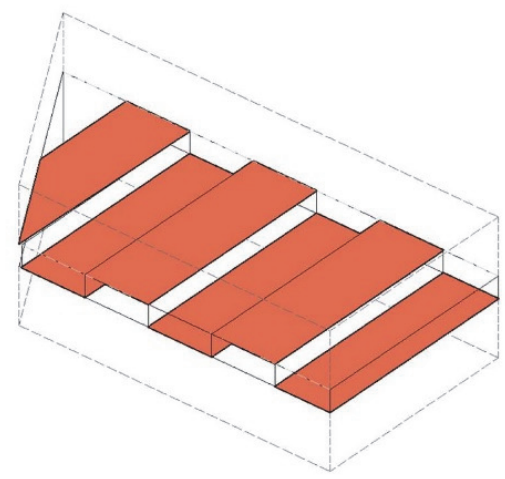

(c)

Figure 15: a) An interlocking interface and its failure planar strips including b) dry joints and c) fracture planes.

Convex contact model addressed in [7] idealizes the stress state at an interface to the internal forces at the centre of the interface including the normal force $f_{n}$, two tangential forces $f_{t 1}$ and $f_{t 2}$ normal to each other, two bending moments normal to each other $b n_{1}$ and $b n_{2}$ and torsion moment $t_{r}$ (Fig. 16a). In this section, instead of the centre of the interface, the internal forces at the intersection point of the meridional thrust-line of a lune and an interface are considered (Fig. 16b and c). A similar approach was previously applied to find the internal forces at the 2D conventional [9] and interlocking interfaces [2] of a semi-circular arch. 
For such a convex model specialized for the hemispherical dome, the constraints on all the six internal forces preventing the mentioned structural failures are as follows: to avoid the block separation, $f_{n}$ must be in compression $\left(f_{n} \leq 0\right)$; two tangential forces are considered along the locks $f_{t 1}$, and normal to the locks $f_{t 2} ; f_{t 1}$ must satisfy the Coulomb's friction law $\left(f_{t 1} \leq \mu f_{n}\right)$, otherwise the block slides along the locks; $f_{t 2}$ and torsion moment $t_{r}$ must be less than the lock shear, bending and torsional resistance, as explained later; lastly, since the flow of forces, within the dome thickness, passes through the contact points of the convex model, $b n_{1}$ and $b n_{2}$ are zero and ignored (Fig. 16c).

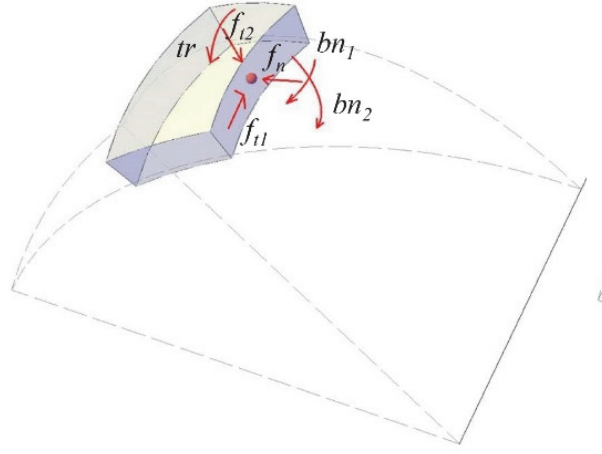

(a)

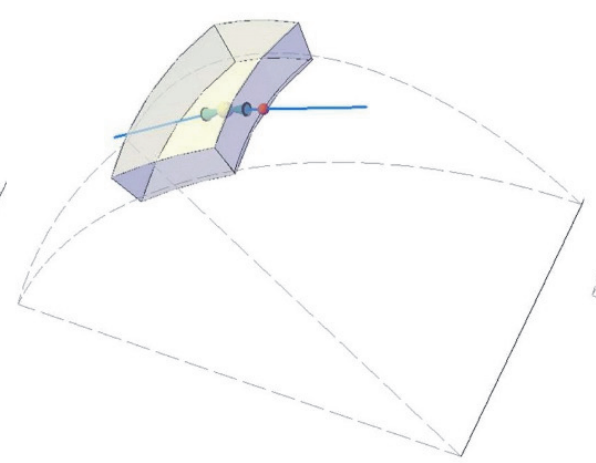

(b)

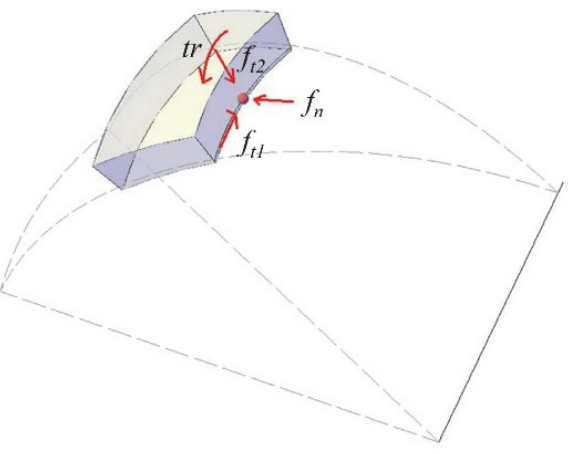

(c)

Figure 16: a) Contact point at the interface centroid according to the convex contact model in [7]; b) contact point as the intersection point of the interface and the network of forces according to the proposed convex contact model for the hemispherical dome; c) internal force on the contact point of the proposed convex contact model.

The lock bending, shear, and torsional resistance can be found as follows: first of all, following [2] bending failure is neglected at the fracture plane through $g \leq h$, where $g$ and $h$ are the thickness and height of the lock as already introduced above (Fig. 1). This means that the lock is thick enough so that, when subjected to a lateral force, it does not bend generating crack where the lock is connected to the main body of the lock.

Besides, a conservative formulation to avoid both shear and torsional failures at locks is herein proposed. The tangential forces normal to a lock can be distributed uniformly or non-uniformly. If the force is uniformly distributed on lock $k$ (Fig. $17 \mathrm{a})$, its limiting shear value $T_{k y}$ equals $\left(t_{y} b_{k}\right)$, where $t_{y}=(g \tau)$ is the yielding force per unit length, $\tau$ is the material shear strength, $g$ is the lock thickness and $b_{k}$ is length of the lock, calculated through Eqns. (25) to (31).

When the force is non-uniformly distributed on lock $k$ (Fig. 17b), the lock may slide and/or twist after reaching the limiting value. For this case, the shear resistance of the lock is lower than the limiting value, since for a non-uniformly distributed force, whose resultant equals $t_{y} b_{k}$, there would be at least one point at which the force per unit length $t_{b}$ is more than $t_{y}$. For such a non-uniformly distributed force, the overall shear resistance of the lock can be reduced to $T_{k y}=\left(c f_{k} t_{y} b_{k}\right)$, where $c f_{k}$ is a coefficient less than one (Fig. 17b). Applying this coefficient, a combination of shear and torsion of the lock is considered, which becomes pure torsion for $c f_{k}=0$ and pure shear for $c f_{k}=1$ [7].

Given $f_{t 2}$, the tangential force at each lock can be considered as a component of $f_{t 2}\left(f_{t 2}\right)^{k}$ subjected to an intersection point of $f_{t 2}$ and the centreline of the $k^{\text {th }}$ lock (Fig. 17c and d). Then, the following scalar summation represents the relation between $f_{t 2}$ and its components:

$$
f_{t 2}=\sum_{k=0}^{m-1 / 2} f_{t 2}^{k}
$$

When the intersection point of $f_{t 2}$ and the centreline of the $k^{\text {th }}$ lock is not the centreline mid-point, the equivalent distributed force of $f_{t 2}{ }^{k}$ is spread along the centreline non-uniformly. Therefore, $f_{t 2}{ }^{k} c f_{k} t_{y} b_{k}$.

In sum, the interlocking interface in Fig. 18 can be designed so that the fracture occurs on a flat face, i.e. fracture occurs only at one of the two interlocked blocks where its locks are attached to the main body of that block (Fig. 18), considering an overall shear resistance as:

$$
f_{t 2}=\sum_{k=0}^{m-1 / 2} f_{t 2}^{k} \leq t_{y} \sum_{k=0}^{m-1 / 2} b_{k} c f_{k}
$$


where the coefficient $c f_{k}$ for each lock can be obtained through experimental investigation on different interlocking interface geometries.

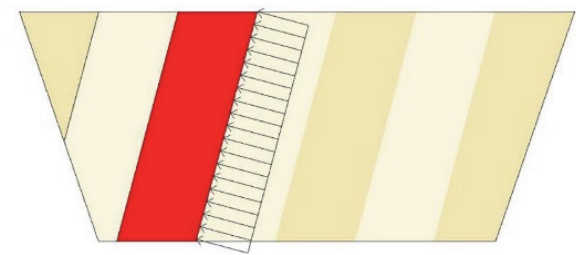

$t_{b} \leq t_{y}$

(a)

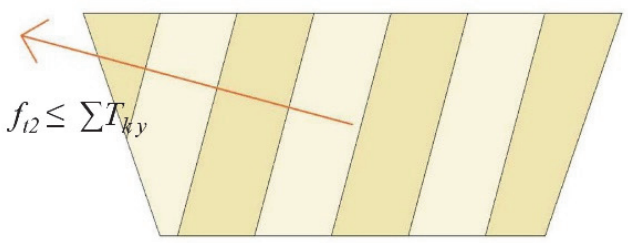

(c)

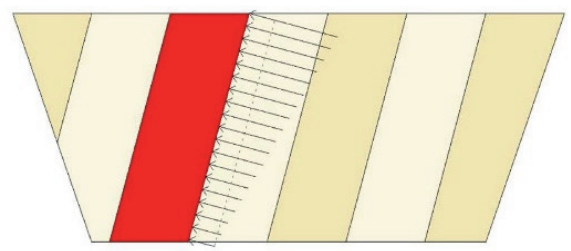

$t_{b} \leq c f t_{y}$

(b)

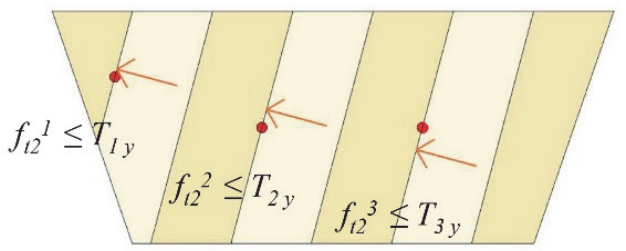

(d)

Figure 17: a) and b) Force distribution and shear resistance for a lock; c) and d) a conservative formulation for shear resistance of the interface within the convex contact model framework.
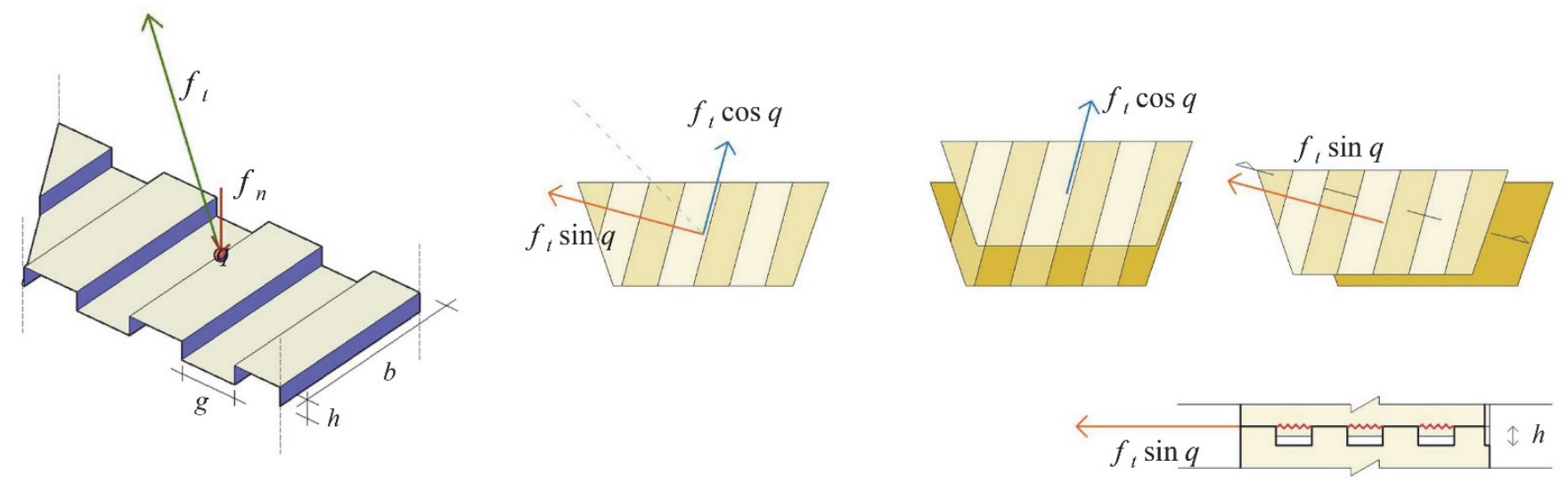

Figure 18: The orthotropic sliding resistance of an interlocking block governed by the Coulomb's friction law and the shear resistance of the locks in two normal directions.

Considering $f_{t 1}$ and $f_{t 2}$ two components of the tangential force $f_{t}$, and $q$ the angle between the tangential force $f_{t}$ and the locks, the sliding constraint of an interlocking interface as long as the locks are not cracked is (Fig. 18):

$$
\left\{\begin{array}{c}
f_{t} \sin q \leq \tau_{k} g \sum_{i=0}^{m-1 / 2} b_{i} k_{i} \\
f_{t} \cos q \leq \mu f_{n}
\end{array}\right.
$$

Once all the locks are fractured and separated from the main body, the interface is turned to be a conventional interface. Thus, the non-linear sliding constraint can be formulated as: 


$$
\left\{\begin{array}{l}
f_{t} \leq \frac{\tau_{k} g}{\sin q} \sum_{i=0}^{m-1 / 2} b_{i} k_{i} \rightarrow f_{t} \leq \frac{\mu f_{n}}{\cos q} \\
f_{t} \geq \frac{\tau_{k} g}{\sin q} \sum_{i=0}^{m-1 / 2} b_{i} k_{i} \rightarrow f_{t} \leq \mu f_{n}
\end{array}\right.
$$

In the future, the proposed convex model including the heuristic method for sliding resistance of the interlocking interfaces will be introduced to the revised membrane approach to find the thinnest hemispheric domes with interlocking blocks.

\section{CONCLUSION}

he paper presented two contributions to develop a limit analysis method for hemispherical domes composed of interlocking blocks. First the revision to an existing limit analysis approach using the membrane theory to find the thinnest hemispherical dome is presented. The dome is composed of blocks with isotropic sliding properties governed by the Coulomb's friction law and it is only subjected to its own weight. The base thrust-line was constructed by a number of control points whose coordinates are the optimization variables. The optimization was constrained to meet the developed equilibrium conditions and sliding resistances. The results were obtained for (1) the finite tensile hoop stresses allowed by friction between the blocks assembled by running bond pattern; and for (2) no tensile hoop stresses which occurs in case of assembling the dome using stacked bond pattern. The outcomes showed that the revised formulations provided better results when compared to the other existing methods to find the minimum thickness of a structurally feasible dome, rather than the original formulation in [1]. The paper also demonstrated how the discrete network of forces can be constructed using the meridional thrust-line.

The second issue addressed was the development of a heuristic method to find the orthotropic sliding resistance of the interlocking interface. First, a modelling procedure was proposed to abstract the interface and formulate the geometric properties on the interlocking interface affecting the sliding resistance. Then, adopting the convex contact model, the constraints for the internal forces tangential to the block interfaces within the hemispherical dome were defined.

In further work, the developed constraints will be applied to find the thinnest dome composed of interlocking blocks and the revised limit analysis approach will also be extended to find the minimum thickness of shells with various basic geometries and non-isotropic interfaces.

\section{ACKNOWLEDGEMENTS}

This project has received funding from the European Union's Horizon 2020 research and innovation programme under the Marie Skłodowska-Curie Grant Agreement No. 791235.

\section{REFERENCES}

[1] D'Ayala, D. and Casapulla, C. (2001). Limit state analysis of hemispherical domes with finite friction, Proc. III International Seminar on Structural Analysis of Historical Constructions (SAHC01), Guimarães (Portugal), pp. 617626.

[2] Casapulla, C., Mousavian, E. and Zarghani, M. (2019). A digital tool to design structurally feasible semi-circular masonry arches composed of interlocking blocks, Comput. Struct., 221, pp. 111-126.

DOI: $10.1016 /$ j.compstruc.2019.05.001

[3] Livesley, R.K. (1978). Limit analysis of structures formed from rigid blocks, Int. J. Numer. Meth. Eng., 12(12), pp. 1853-1871. DOI: $10.1002 /$ nme.1620121207

[4] Block, P.P.C.V. (2009). Thrust network analysis: exploring three-dimensional equilibrium, Ph.D. Thesis, Massachusetts Institute of Technology, Cambridge (USA).

[5] O’Dwyer, D. (1999). Funicular analysis of masonry vaults, Comput. Struct., 73(1-5), pp. 187-197. 
DOI: 10.1016/S0045-7949(98)00279-X

[6] Livesley, R.K. (1992). A computational model for the limit analysis of three-dimensional masonry structures, Meccanica, 27(3), pp. 161-172. DOI: 10.1007/BF00430042

[7] Casapulla, C. and Maione, A. (2018). Modelling the dry-contact interface of rigid blocks under torsion and combined loading: concavity vs. convexity formulation, Int. J. Nonlin. Mech., 99, pp. 86-96.

DOI: 10.1016/j.ijnonlinmec.2017.11.002

[8] Heyman, J. (1969). The safety of masonry arches, Int. J. Mech. Sci., 11(4), pp. 363-385.

DOI: $10.1016 / 0020-7403(69) 90070-8$

[9] Casapulla, C. and Lauro, F. (2000). A simple computation tool for the limit-state analysis of masonry arches. Proc. 5th International Congress on Restoration of Architectural Heritage (Firenze 2000), Firenze (Italy), pp. 2056-2064.

[10] [10] Block, P.P.C.V. (2005). Equilibrium systems: Studies in masonry structure, M.S. Thesis, Massachusetts Institute of Technology, Cambridge (USA).

[11] Velilla, C., Alcayde, A., San-Antonio-Gómez, C., Montoya, F.G., Zavala, I. and Manzano-Agugliaro, F. (2019). Rampant arch and its optimum geometrical generation, Symmetry, 11(5), art. no. 627. DOI: $10.3390 / \mathrm{sym} 11050627$

[12] Tempesta, G. and Galassi, S. (2019). Safety evaluation of masonry arches. A numerical procedure based on the thrust line closest to the geometrical axis, Int. J. Mech. Sci., 155, pp. 206-221. DOI: 10.1016/j.ijmecsci.2019.02.036

[13] Beatini, V., Royer-Carfagni, G. and Tasora, A. (2019). Modeling the shear failure of segmental arches, Int. J. Sol. Struct., 158, pp. 21-39. DOI: 10.1016/j.ijsolstr.2018.08.023

[14] Aita, D., Barsotti, R. and Bennati, S. (2019). Looking at the collapse modes of circular and pointed masonry arches through the lens of Durand-Claye's stability area method, Arch. Appl. Mech., in press. DOI: 10.1007/s00419-01901526-z

[15] Di Carlo, F., Coccia, S. and Rinaldi, Z. (2018). Collapse load of a masonry arch after actual displacements of the supports, Arch. Appl. Mech., 88(9), pp. 1545-1558. DOI: 10.1007/s00419-018-1386-6

[16] Rizzi, E., Rusconi, F. and Cocchetti, G. (2014). Analytical and numerical DDA analysis on the collapse mode of circular masonry arches, Eng. Struct., 60, pp. 241-257. DOI: 10.1016/j.engstruct.2013.12.023

[17] Heyman, J. (1995). The Stone Skeleton: structural engineering of masonry architecture, Cambridge University Press, Cambridge (UK).

[18] Lau, W.W. (2006). Equilibrium analysis of masonry domes, Ph.D. Thesis, Massachusetts Institute of Technology, Cambridge (USA).

[19] Beatini, V., Royer-Carfagni, G. and Tasora, A. (2019). A non-smooth-contact-dynamics analysis of Brunelleschi's cupola: an octagonal vault or a circular dome? Meccanica, 54(3), pp. 525-547. DOI: 10.1007/s11012-018-00934-9

[20] Pavlovic, M., Reccia, E. and Cecchi, A. (2016). A procedure to investigate the collapse behavior of masonry domes: some meaningful cases, Int. J. Archit. Herit., 10(1), pp. 67-83. DOI: 10.1080/15583058.2014.951797

[21] D'Ayala, D.F. and Tomasoni, E. (2011). Three-dimensional analysis of masonry vaults using limit state analysis with finite friction, Int. J. Archit. Herit., 5(2), pp. 140-171. DOI: 10.1080/15583050903367595

[22] Chiozzi, A., Milani, G., Tralli, A.M., A Genetic Algorithm NURBS-based new approach for fast kinematic limit analysis of masonry vaults, Comput. Struct., 182, pp. 187-204. DOI: 10.1016/j.compstruc.2016.11.003

[23] Mousavian, E. and Mehdizadeh Saradj, F. (2018). Automated detailing and stability analysis of under-construction masonry vaults, Journal of Architectural Engineering-ASCE, 24(3), art. no. 04018014. DOI: 10.1061/(ASCE)AE.1943-5568.0000314

[24] De Piano, M., Modano, M., Benzoni, G., Berardi, V.P. and Fraternali, F. (2017). A numerical approach to the mechanical modeling of masonry vaults under seismic loading, Ingegneria Sismica, 34(4), pp. 103-119.

[25] Calderini, C., Rossi, M., Lagomarsino, S., Cascini, L. and Portioli, F. (2017). Experimental and numerical analysis of seismic response of unreinforced masonry cross vaults, Proc. 7th International Conference on Advances in Experimental Structural Engineering (AESE 2017), Pavia (Italy), pp. 659-670. DOI: 10.7414/7aese.T5.136

[26] Baggio, C., and Trovalusci, P. (2016). 3D limit analysis of roman groin vaults, Proc. 16th International Brick and Block Masonry Conference (IBMAC 2016) Padova (Italy), pp. 1023-1028.

[27] Lourenço, P.B., Rots, J.G. and Blaauwendraad, J. (1995). Two approaches for the analysis of masonry structures: micro and macro-modeling, Heron, 40(4), pp. 1-28.

http://resolver.tudelft.nl/uuid:c39b29ab-3c75-47db-9cb5-bf2b1c678f1f

[28] Li, T. and Atamturktur, S. (2013). Fidelity and robustness of detailed micromodeling, simplified micromodeling, and macromodeling techniques for a masonry dome, Journal of Performance of Constructed Facilities, 28(3), 480-490.

[29] Olmati, P., Gkoumas, K. and Bontempi, F. (2019). Simplified FEM modelling for the collapse assessment of a masonry vault, Frattura ed Integrita Strutturale, 13(47), pp. 141-149. DOI: 10.3221/IGF-ESIS.47.11 
[30] Bui, T.T., Limam, A., Sarhosis, V. and Hjiaj, M. (2017). Discrete element modelling of the in-plane and out-of-plane behaviour of dry-joint masonry wall constructions, Eng. Struct., 136, pp. 277-294.

DOI: $10.1016 /$ j.engstruct.2017.01.020

[31] Simon, J. and Bagi, K. (2016). Discrete element analysis of the minimum thickness of oval masonry domes, Int. J. Archit. Herit., 10(4), pp. 457-475. DOI: 10.1080/15583058.2014.996921

[32] Cannizzaro, F., Pantò, B., Caddemi, S. and Caliò, I. (2018). A Discrete Macro-Element Method (DMEM) for the nonlinear structural assessment of masonry arches, Eng. Struct., 168, pp. 243-256.

DOI: $10.1016 /$ j.engstruct.2018.04.006

[33] Giresini L., Sassu M., Butenweg C., Alecci V. and De Stefano M. (2017). Vault macro-element with equivalent trusses in global seismic analyses, Earthq. Struct., 12(4), pp. 409-23. DOI: 10.12989/eas.2017.12.4.409

[34] Giresini L., Casapulla C., Denysiuk R., Matos J and Sassu M. (2018). Fragility curves for free and restrained rocking masonry façades in one-sided motion, Eng. Struct., 164, pp. 195-213. DOI: 10.1016/j.engstruct.2018.03.003

[35] Giresini L., Sassu M. and Sorrentino L. (2018). In situ free-vibration tests on unrestrained and restrained rocking masonry walls, Earthq. Eng. Struct. D., 47(15), pp. 3006-3025. DOI: 10.1002/eqe.3119

[36] Gilbert, M., Casapulla, C. and Ahmed, H.M. (2006). Limit analysis of masonry block structures with non-associative frictional joints using linear programming, Comput. Struct., 84(13-14), pp. 873-887. DOI: $10.1016 /$ j.compstruc.2006.02.005

[37] Casapulla, C. and Argiento, L.U. (2018). In-plane frictional resistances in dry block masonry walls and rocking-sliding failure modes revisited and experimentally validated, Compos. Part B-Eng., 132, pp. 197-213. DOI: $10.1016 /$ j.compositesb.2017.09.013

[38] Liu, H., Liu, P., Lin, K. and Zhao, S. (2016). Cyclic behavior of mortarless brick joints with different interlocking shapes, Materials, 9(3), art. no. 166. DOI: $10.3390 / \mathrm{ma} 9030166$

[39] Totoev, Y. (2015). Design procedure for semi interlocking masonry, Journal of Civil Engineering and Architecture, 9 , pp. 517-525. DOI: 10.17265/1934-7359/2015.05.003

[40] Hossain, M.A., Totoev, Y. and Masia, M.J. (2016). Friction on mortar-less joints in semi interlocking masonry. Proc. 16th International Brick and Block Masonry Conference (IBMAC 2016) Padova (Italy), pp. 1635-1643.

[41] Pantò, B., Silva, L., Vasconcelos, G. and Lourenço, P.B. (2019). Macro-modelling approach for assessment of out-ofplane behavior of brick masonry infill walls, Eng. Struct., 181, pp. 529-549. DOI: 10.1016/j.engstruct.2018.12.019

[42] Dyskin, A.V., Pasternak, E. and Estrin, Y. (2012). Mortarless structures based on topological interlocking, Front. Struct. Civ. Eng., 6(2), pp. 188-97. DOI: 10.1007/s11709-012-0156-8

[43] Estrin, Y., Bréchet, Y., Dunlop, J. and Fratzl, P. (2019). Architectured Materials in Nature and Engineering, Springer Nature Switzerland AG.

[44] Ali, M., Gultom, R. J. and Chouw, N. (2012). Capacity of innovative interlocking blocks under monotonic loading, Constr. Build. Mater., 37, pp. 812-821. DOI: 10.1016/j.conbuildmat.2012.08.002

[45] Fang, D. and Mueller, C.T. (2018). Joinery connections in timber frames: analytical and experimental explorations of structural behavior, Proc. Annual Symposium of the International Association for Shell and Spatial Structures (IASS), pp. 1-8.

[46] MATLAB, (2019) https://www.mathworks.com/help/optim/ug/fminimax.html. 